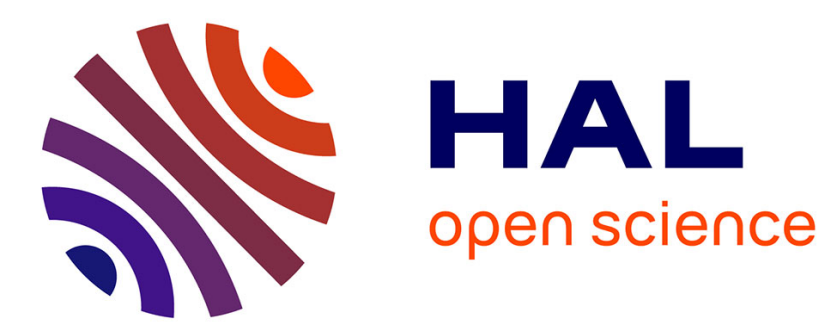

\title{
Determination of aluminum-air burning velocities using PIV and Laser sheet tomography
}

\author{
R. Lomba, P. Laboureur, C. Dumand, Christian Chauveau, F. Halter
}

\section{To cite this version:}

R. Lomba, P. Laboureur, C. Dumand, Christian Chauveau, F. Halter. Determination of aluminum-air burning velocities using PIV and Laser sheet tomography. Proceedings of the Combustion Institute, 2019, 37 (3), pp.3143-3150. 10.1016/j.proci.2018.07.013 . hal-01991739

\section{HAL Id: hal-01991739 \\ https://hal.science/hal-01991739}

Submitted on 10 Mar 2019

HAL is a multi-disciplinary open access archive for the deposit and dissemination of scientific research documents, whether they are published or not. The documents may come from teaching and research institutions in France or abroad, or from public or private research centers.
L'archive ouverte pluridisciplinaire HAL, est destinée au dépôt et à la diffusion de documents scientifiques de niveau recherche, publiés ou non, émanant des établissements d'enseignement et de recherche français ou étrangers, des laboratoires publics ou privés. 


\title{
Determination of aluminum-air burning velocities using PIV and Laser sheet tomography
}

\author{
R. Lomba ${ }^{\mathrm{a}, \mathrm{b}}$, P. Laboureur ${ }^{\mathrm{a}, \mathrm{b}}$, C. Dumand ${ }^{\mathrm{b}}$, C. Chauveau ${ }^{\mathrm{a}}$, F. Halter ${ }^{\mathrm{a}, *}$ \\ ${ }^{a}$ CNRS-ICARE, 1 C Avenue de la Recherche Scientifique, 45071 Orléans Cedex 2, France \\ ${ }^{b}$ Groupe PSA, Route de Gisy, 78140 Vélizy-Villacoublay, France
}

\begin{abstract}
In a context of growing concerns over climate change, aluminum has the potential to serve as a dense energy carrier in order to replace fossil fuels and reduce greenhouse gases emissions. Indeed, its combustion in air may provide carbonfree energy for applications in which a high-energy storage capacity is required. However, attempts of designing a metal-fueled combustor will conflict with a relatively large dispersion of the burning velocity values reported in the literature, even when similar powders are used. This uncertainty is partially due to the range of experimental conditions and techniques used on those previous studies. In the present work, an experimental Bunsen-type aluminum-air burner is introduced. It is shown that the setup is capable of generating stable dust suspensions under well-controlled conditions. The stabilized aluminum-air flames are studied using emission spectroscopy, Particle Image Velocimetry, laser sheet tomography, and direct visualization of the $\mathrm{AlO}(\mathrm{g})$ emissions. The measured burning velocities are then compared to previous results obtained for similar powders as a function of dust concentration. A reasonable agreement is obtained, and it is shown that
\end{abstract}

\footnotetext{
*Corresponding author:

Email address: fabien.halterecnrs-orleans.fr(F. Halter)
} 
metal flame tomography can yield a more precise indicator of the flame front position than $\mathrm{AlO}(\mathrm{g})$ emissions, helping to reduce the data scatter regarding dust-air burning velocities.

Keywords:

Aluminum, Burning velocity, Flame temperature, Dust flame

\section{Introduction}

Aluminum powders present an interesting potential as a carbon-free energy carrier [1]. Indeed, they are highly energetic, with gravimetric and volumetric energy contents that are comparable to hydrocarbon fuels. Its main combustion product in atmospheric air is alumina, which can be reduced back to aluminum through low-carbon pathways [2], provided that the energy mix used is mainly composed of renewable or nuclear energy. For the transportation sector, burning aluminum powders directly with atmospheric air could provide the specific energy and power density that batteries and hydrogen storage materials are still struggling to achieve. In this context, this work focuses on fine micron-sized aluminum powders, since they represent an interesting compromise regarding fast reaction rates associated with small (high surface-to-volume ratio) particles, while avoiding the safety issues and lower energy content (due to alumina layer) characteristic of aluminum nanoparticles.

In order to better evaluate this potential, it is necessary to know the aluminumair aerosol laminar burning velocity, which is a fundamental property describing the mixture's reactivity, heat production, and heat transfer. However, experimental data on the burning velocity of metal-air aerosols are still scarce and scattered. The first of these burning velocity measurements were made by Cassel [3] in his 
pioneering work on aluminum dust Bunsen flames. Aslanov et al. [4] developed a particle dispersion system and studied the flame propagation in a tube. This dispersion system was also used under similar conditions by Boichuk et al. [5], and to feed a stabilized dust flame burner introduced by Goroshin et al. [6]. Risha et al. [7] later developed a similar dust burner and measured the burning velocities of Al-air flames. Julien et al. [8] measured the flame speed of a spherical Al$\mathrm{O}_{2} / \mathrm{Ar}$ flame propagating at constant pressure and extracted the burning velocity from the expansion coefficient calculated by chemical equilibrium. Despite the fact that most of those studies used a similar aluminum powder and dispersion system, the burning velocity values presented range from $10 \mathrm{~cm} / \mathrm{s}$ to $32 \mathrm{~cm} / \mathrm{s}$.

In addition, some unique aspects regarding the propagation of metallic flames were observed, which increases the complexity of the phenomenon. The instabilities linked to the discreet nature of solid fuels were observed [9, 10], and the very luminous nature of the aluminum flame in a non-transparent medium, which is the dust cloud, lead to interrogations concerning the role of radiation on the flame propagation [8]. These effects raise even the question of whether a nonstretched laminar burning velocity can be properly defined for metal dust clouds [11]. Therefore, in order to reduce such uncertainties on the burning velocity measurements, it is necessary to work under well-controlled conditions.

In this work, the development and characterization of a laminar dust burner inspired by previous works in the literature [6,12] are presented. Various optical diagnostics, such as high-speed tomography, direct visualization of $\mathrm{AlO}(\mathrm{g})$ emissions and spectroscopy, were conducted in order to measure the flame properties. The results are then compared with the existing literature, and analyzed in a context of zero-carbon power generation. 


\section{Experimental setup}

The aluminum powder used in this work is pure $(>99.8 \%)$ and spherical, with a Sauter mean diameter of $7.1 \mu \mathrm{m}$ and a narrow size distribution. The powder characteristics are further described in a previous work [13]. A schematic of the experimental apparatus used is shown in Fig. 1.

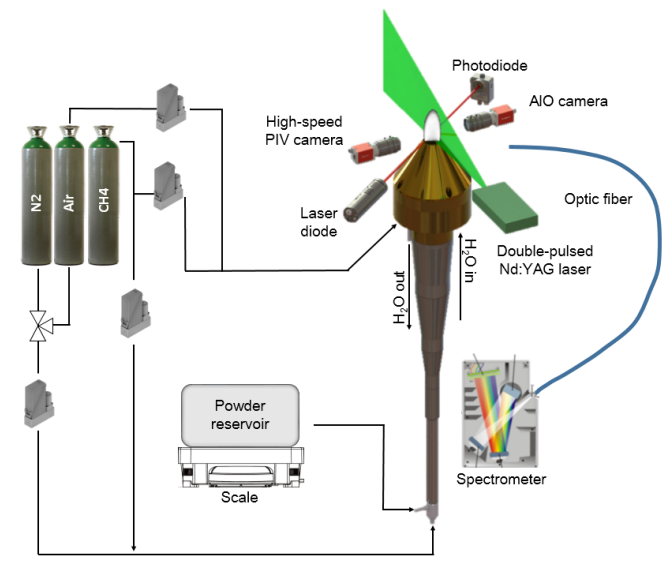

Figure 1: Schematic of the experimental setup.

It consists of a stirred powder reservoir, which is placed over a scale and connected to one end of an ejector nozzle. An air flow is supplied to the other end of the ejector nozzle, creating a depressurization inside thereof. This depressurization generates a suction flow of aluminum particles and atmospheric air, and disperses the powder into the main body of the burner, forming a turbulent flow. This flow is then laminarized and finally contracted at the exit. The contraction profile is such that boundary layer is crushed and a flat velocity profile is obtained at the burner exit.

Around the burner rim, an annular methane-air pilot flame of $1.5 \mathrm{~mm}$ of thickness is stabilized in order to improve the flame stabilization. Ignition is then 
achieved by supplying a methane flow rate to the main flow of the burner, which is ignited by the annular pilot flame, creating a hybrid $\mathrm{Al} / \mathrm{CH}_{4}$-air flame structure. Once the hybrid flame is stable, the methane flow rate is removed, thus allowing an aluminum-air flame to stabilize itself at the burner exit. The flame is then characterized using a spectrometer, a tomography setup, a camera and filter set in order to visualize flame emissions.

The aerosol flow at the burner exit is characterized by a particle image velocimetry (PIV) setup, using the aluminum particles themselves as trackers. An example of PIV image used for studying the aerosol generation is given in Fig. 2(a), where a good qualitative spatial homogeneity of the dust concentration afar from the boundary layers can be inferred. Under typical operating conditions, the Stoke's number associated with the particles is $S t k \approx 10^{-3} \ll 1$, implying that aluminum particles closely follow the air streamlines and are stationary with respect to the gaseous phase. The mean velocity profile extracted exactly at the burner exit is shown in Fig. 2(b). The profile is flat and symmetric, and the total gaseous flow rate is obtained by integrating the mean velocity profile.

The total air flow rate $Q_{T}$ is calibrated as a function of the powder mass flow rate $\dot{m}$, thus allowing the definition of a nominal dust concentration at the burner entrance, $\dot{m} / Q_{T}$. The powder mass flow rate is obtained through the scale measurements of the dust reservoir mass, as illustrated in Fig. 3(a), in which $m_{T}$ is the total mass of powder dispersed in a given run. However, in order to obtain the dust concentration at the burner exit $B$, it is still necessary to take into account the powder accumulation at the walls inside the experimental device.

For such, two distinct methods were used. The first one consists of comparing the weighing measurements described above with the mass difference of the 

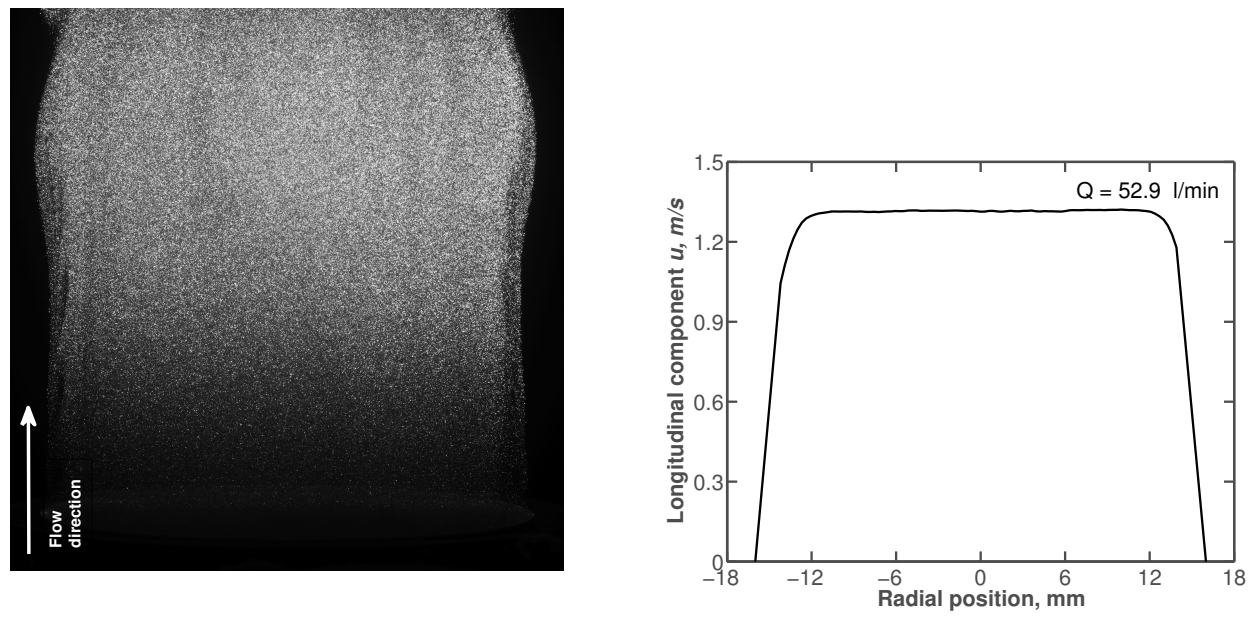

(a) Example of PIV image of the non-reacting (b) Mean velocity profile extracted at the burner flow. exit.

Figure 2: PIV results characterizing the aerosol flow.

burner itself before and after a run, $d M: B=\left(1-d M / m_{T}\right)\left(\dot{m} / Q_{T}\right)$. The second method consists of studying the attenuation of a laser beam crossing the dust flow at the burner exit (Fig.1) with Beer-Lambert's law and the refractive indexes given in [14] in order to obtain the instantaneous dust concentration. The laser attenuation measurements have shown that the concentration is temporally stable.

A calibration campaign comprised of several measurement points with distinct mass flow rates and run duration was undertaken, and the resulting calibration law is shown on Fig.3(b). These results show that the weighing and laser attenuation measurements are in good agreement. This serves as an indicator that the mean particle size at the burner exit corresponds to the powder's nominal mean particle size. The resulting calibration law is able to determine the dust concentration within a margin of $\pm 25.3 \mathrm{~g} / \mathrm{cm}^{3}$ with a confidence level of $95 \%$. This precision is 
acceptable when compared to the $310 \mathrm{~g} / \mathrm{cm}^{3}$ stoichimetric equivalence ratio.

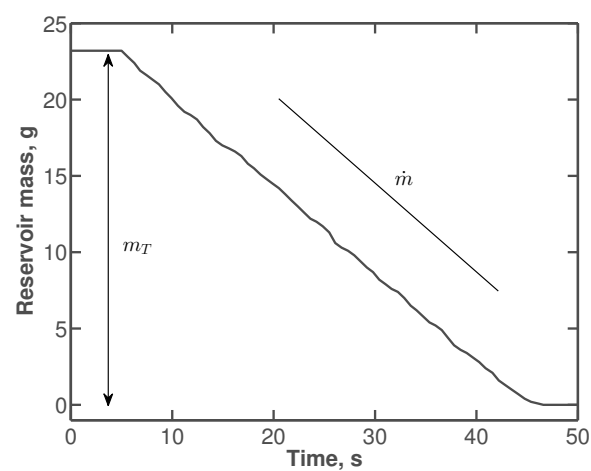

(a) Temporal evolution of the dust reservoir

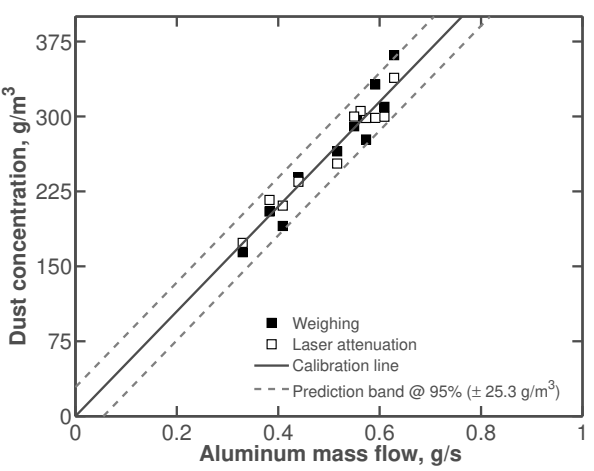

(b) Dust concentration calibration law. mass.

Figure 3: PIV results characterizing the aerosol flow.

\section{Results}

Once stabilized at the burner exit, the metal dust flame produces a very intense light that can be analyzed through emission spectroscopy. An optical fiber connected to a spectrometer (Ocean Optics HR4000) is focused on the flame zone. The light signal emitted by the combustion of the metal particles is composed of two distinct contributions. A first part is due to the thermal excitation of the condensed combustion products, and corresponds to a continuous emission background. It was observed that this emission background can be well represented by an increasing straight line between $400 \mathrm{~nm}$ and $600 \mathrm{~nm}$. Therefore, a fitting algorithm is adjusted to the condensed phase emissions and thereafter subtracted from the flame spectrum. The resulting spectrum after this subtraction corresponds to the emission lines originating from the gaseous species. The main features of the gaseous part of the aluminum flame spectrum are the aluminum vapor lines 
at $394.3 \mathrm{~nm}$ and $396 \mathrm{~nm}$, and the $B^{2} \Sigma^{+}-X^{2} \Sigma^{+}$(blue-green) band system of gaseous aluminum monoxide.

It is possible to determine the temperature which better describes the observed $\mathrm{AlO}$ emissions. By assuming a thermal equilibrium between all the species in the reaction zone, the calculated $\mathrm{AlO}$ temperature can be associated to the gaseous phase temperature. The fitting process used to determine this flame temperature is described by [15], and consists of a line-by-line simulation of the AlO spectrum based on the spectroscopic constants and relative band strengths from [16, 17]. Figure 4(a) illustrates an example of an emission spectrum fitting result, obtained for an aluminum-air equivalence ratio of $\phi=1.3$. The emission line at $519.3 \mathrm{~nm}$ observed experimentally is not described in the fitting algorithm, and therefore is not taken into account for temperature calculation. Figure 4(b) shows the results obtained as a function of the dust concentration of the aerosol. Each point in this figure corresponds to an average of 100 spectra. The gaseous phase temperature is observed to be constant for all the dust concentrations studied, and is about 3150 $\mathrm{K} \pm 180 \mathrm{~K}$. This value is $400 \mathrm{~K}$ below the adiabatic flame temperature, and is in good agreement with the temperature measurements of the condensed phase carried out in previous experiments in a constant volume chamber [13].

The burning velocity $S_{L}$ is defined as the velocity upstream of the preheating zone at which fresh gases move through the combustion wave in the direction normal to the wave surface [18]. This interface is defined in the following as the flame surface. In the dust burner setup, the mass conservation principle yields the relationship $S_{L}=Q_{T} / A$, where $Q_{T}$ is the total airflow at the burner exit, and $A$ is the surface area of the flame. The latter can be obtained by the numerical integration of the rotational figure formed by the flame contour. 


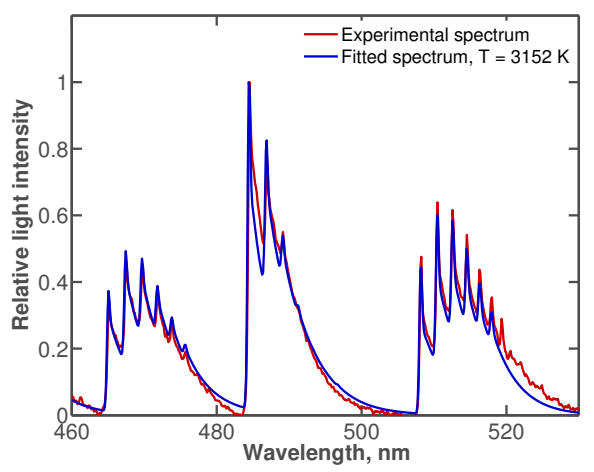

(a) Example of a simulated spectrum superposed to the experimental AlO.

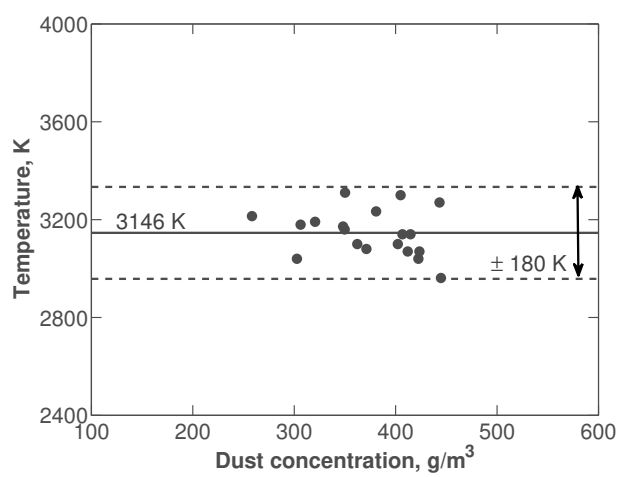

(b) Aluminum-air flame temperatures as a function of the aluminum dust concentration.

Figure 4: Temperature fitting procedure and results.

Two distinct methods for contour detection were used in this study. The first one is a laser sheet tomography of the flame, which constitutes an instantaneous planar visualization of the Mie-scattered laser light $(532 \mathrm{~nm})$ by the condensed phase of the flow. An example of a tomography image is given in Fig.5(a). In this image, three different regions can be observed: a fresh mixture region, where the laser scattering is identical to the cold-flow PIV images (Fig.2(a)); a dark region; and a burned mixture region. Another example is given in Fig. 5(b), with the distinction that the laser power is weaker and that it mainly illuminates the lower part of the flame. Camera exposure was set accordingly. As a result, flame emissions at $532 \mathrm{~nm}$ are no longer drowned in the laser intensity, and are still discernible. The second method is the direct visualization of the $\mathrm{AlO}(\mathrm{g})$ emissions, illustrated in Fig.5(c).

The burned gases expansion and the streamlines deviation at the reaction zone can be observed in the mean velocity field obtained by PIV measurements of the high-speed tomography images, as shown in Fig. 6. The analysis of each velocity 


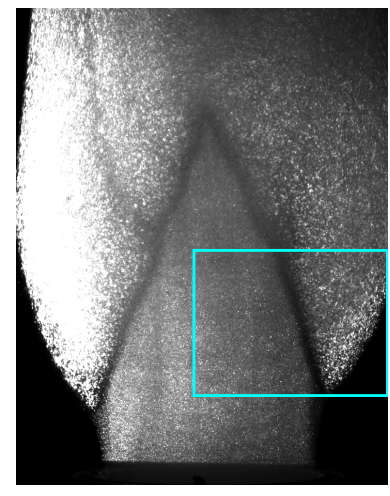

(a) Tomography image of an aluminum-air flame.

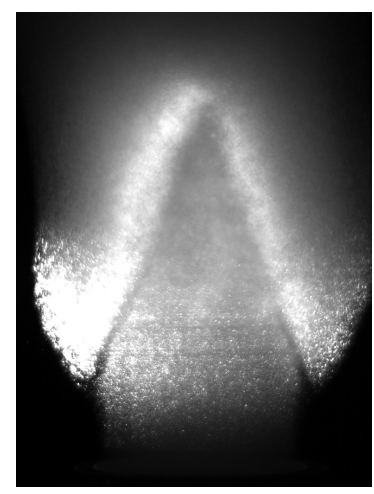

(b) Tomography image with lower laser power.

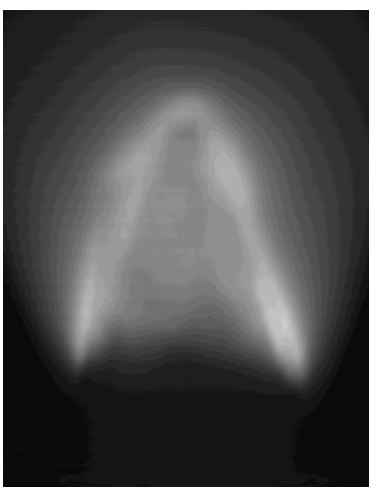

(c) Mean image of the $\mathrm{AlO}$ emissions of an aluminumair flame.

Figure 5: Different visualization methods for an aluminum-air $(\phi=1.22)$.

field is used for the interpretation of the tomography images and for calibrating the image processing algorithm. Indeed, the contour detection was empirically calibrated in order to match the minimum normal velocity isoline. The calibration procedure is briefly described hereafter.

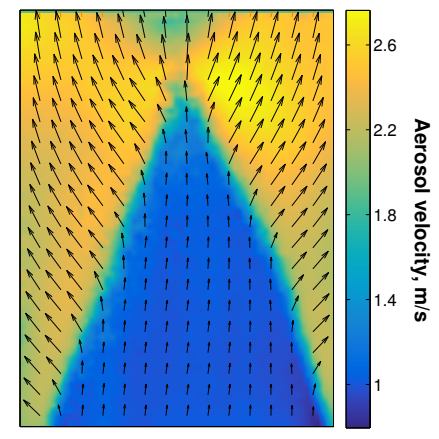

Figure 6: Mean velocity field.

First, the dark inner zone contour is detected by an image processing algorithm. A set of 10 points is then defined along this contour's lateral borders, and 
the orthogonal velocity profiles are extracted at these points. For determining the orthogonal direction, the raw, unfiltered contour is locally approximated by a straight line. Indeed, the presence of inter-particle spacing is responsible for a non-physical roughening of this contour, and this approximation becomes a necessary step for determining the combustion wave orientation.

The binary tomography image is then thickened using a Gaussian filter, and subsequently binarized again. The threshold for this last operation minimizes the error between the detected contour position and the minimum aerosol velocity for the defined set of points. On average, the contour position is displaced of $1.21 \mathrm{~mm}$, and the mean standard deviation of the error between the calibrated contour and the position of minimum normal velocity is of $0.24 \mathrm{~mm}$. Consequently, and also taking into account the error when determining the total air flow rate, the estimated error when obtaining burning velocities by rotating the calibrated contour is of \pm $1.4 \mathrm{~cm} / \mathrm{s}$. Figure 7(a) illustrates the results of the empirical contour calibration procedure. For the sake of visibility, only the rectangular section in Fig.5(a) is represented.

Figure 7(b) shows the spatial evolution of the velocity normal to the combustion wave along the dashed line in Fig.7(a). The observed behavior of the aerosol velocity is typical of Bunsen-type flames. In the center of the fresh mixture, the streamlines expansion results in a reduction of the aerosol velocity normal to the flame front. The fresh mixture then starts accelerating upstream of the preheating zone, defining the burning velocity as the minimum value in Fig.7(b). Upon entering the flame, the aluminum particles accelerate for a total length of about $4 \mathrm{~mm}$. This length is defined as the thermal, and is composed by the preheating zone, the reaction zone, and the product condensation zone. The time needed for 


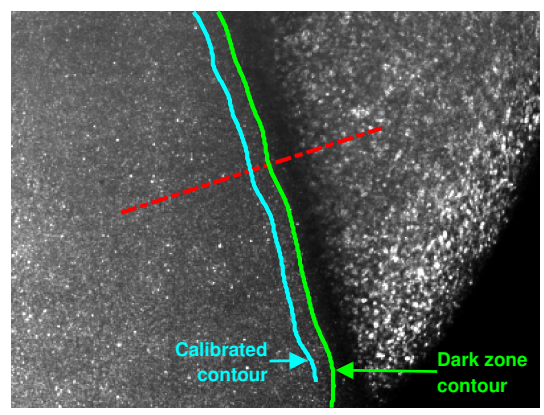

(a) Contour detection for the rectangular sec- (b) tion in Fig.5(a).

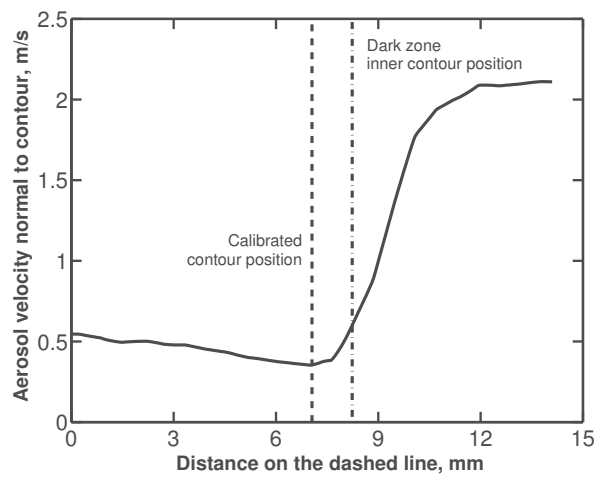

(b) Aerosol velocity in the direction of the dashed line in Fig.7(a) and along its length (from the innermost extremity to the outermost).

Figure 7: Contour detection results and evolution of aerosol velocity normal to the combustion wave.

an aluminum particle to cross this thickness may be evaluated using velocity profiles. This time encompasses both heating time and a reaction time. A residence time of the order of $4 \mathrm{~ms}$ is obtained.

The tangential strain rate $K$ is evaluated based on instantaneous flow field and mean value of $K_{r m s}=57 \mathrm{~s}^{-1}$ was obtained. Therefore, the study of the velocity field of the reacting flow shows that the flame strain rate is weak, and that the dark inner zone contour may be used as an indicator of the flame front position.

The projection of the aerosol velocity in the orthogonal direction of the flame contour provides a method for evaluating the flame structure and the tomography contour detection algorithm. While the exact nature of the observed dark region is unclear, some insight can be obtained from these results. In Fig.7(b), the dot dashed vertical line represents the position of the detected dark inner zone contour obtained through tomography. It is shown that this frontier is located after the 
beginning of the preheating zone. In Fig.5(b), the flame emissions at $532 \mathrm{~nm}$ can be attributed to product condensation, since there are no emission bands from gaseous species in the flame at this wavelength (Fig. 4(a)). Therefore, Fig. 5(b) qualitatively indicates a spatial separation between the dark region and the region where the products condensation is primarily occurring. Therefore, the absence of Mie-scattering in the dark zone can be explained by a drop in particle density after the beginning of the preheating zone coupled with the fact that condensed $\mathrm{Al}_{2} \mathrm{O}_{3}$ is not yet formed.

Burning velocities were also obtained through direct visualizations of the $\mathrm{AlO}(\mathrm{g})$ emissions. Indeed, aluminum monoxide is a well-known combustion intermediate. It is often used as an indicator of the reaction zone position [19] and for estimating burning velocities. In order to isolate the $\mathrm{AlO}(\mathrm{g})$ emissions, the flame was observed through a band-pass filter centered at $488 \mathrm{~nm}$ and with a FWHM of $10 \mathrm{~nm}$. Typically, the mean image for an acquisition time between $5 \mathrm{~s}$ to $10 \mathrm{~s}$ is obtained, such as in Fig.5(c), and is then Abel-deconvoluted using a Fourier-Hankel procedure [20].

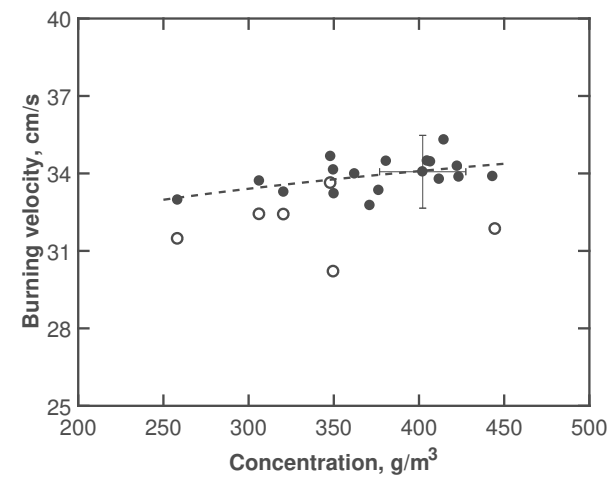

Figure 8: Comparison of the burning velocities obtained with the tomography and direct visualization techniques, as a function of aluminum dust concentration. 
Figure 8 shows a comparison of the burning velocities results yielded by tomography and $\mathrm{AlO}(\mathrm{g})$ direct visualization. For both methods, the burning velocities obtained were observed to be roughly constant for dust concentrations between $0.8<\phi<1.5$, with mean values of $34 \mathrm{~cm} / \mathrm{s}$ when using tomography and $32 \mathrm{~cm} / \mathrm{s}$ when using $\mathrm{AlO}(\mathrm{g})$ visualization. Although a reasonable agreement is obtained, the tomography method is considered to be more reliable. The $\mathrm{AlO}(\mathrm{g})$ method integrates temporal instabilities of the flame position and artificially thickens the flame, which introduces inaccuracies in the determination of the burning velocity. Moreover, combustion of metal suspensions can be optically dense, causing multiple light scatter which makes the spatial determination of the emissions source at a specific wavelength unreliable [21]. The above-mentioned reasons might explain the data scatter from the burning velocities measurements conducted with the $\mathrm{AlO}(\mathrm{g})$ method. Estimated measurement errors for tomographyobtained data are represented by the vertical and horizontal error bars in Fig.8, and are coherent with the observed data scatter.

Figure 9 shows the burning velocity results obtained with flame tomography and compares them with existing literature for aluminum powder at about the same mean diameter. The results are observed to agree the most with a recent study in which burning velocities were obtained from particle velocity profiles and under low-stretch conditions [11]. The stability of the burning velocity as a function of the equivalence ratio was previously observed in [6]. The authors attributed this behavior to the large density difference between air and aluminum particles. Indeed, the addition of aluminum to the aerosol doesn't dilute the oxygen concentration, and the burning rate at each individual particle remains roughly constant. It can also be observed in Fig.9 that the available data is dispersed over 
a wide range of values, despite similar powder sizes and, in most cases, similar aerosol generation devices. The results obtained in this work also present a lower reproducibility error when compared to previous works, highlighting the importance of working under well-controlled conditions and using optical diagnostics suited for multiphase metal combustion.

\section{Conclusions}

The dust burner presented in this work is capable of generating a dust aerosol with homogeneous dust concentration and a flat velocity profile. As a result, the experimental setup is capable of stabilizing aluminum-air flames at low strain rates and extracting reliable burning velocity measurements through the use of instantaneous flames contour detection using high-speed tomography. Regarding the use of aluminum-air combustion for power generation, it is interesting to note that the burner device has an estimated power output of about $8 \mathrm{~kW}$. Indeed, at a mean powder diameter of $7 \mu \mathrm{m}$, the results presented in this work show that aluminum should be as reactive as classical hydrocarbon fuels, presenting similar specific energies and similar burning velocities. Therefore, metals, and in particular aluminum, can be considered as a potential candidate for a clean, renewable and dense energy carrier.

\section{Acknowledgments}

Support for this work was provided by Groupe PSA, as part of the OpenLabEnergetics collaboration between Groupe PSA and Université d'Orléans for clean energy technologies. 


\section{References}

[1] E. I. Shkolnikov, A. Z. Zhuk, M. S. Vlaskin, Renew. Sust. Energ. Rev. 15 (2011) 4611-4623.

[2] J. Keniry, JOM 53 (2001) 43-47.

[3] H. M. Cassel, Report of Investigations 6551. U.S. Department of Interior, Bureau of Mines, Washington, DC. (1964).

[4] S. K. Aslanov, V. G. Shevchuk, Y. N. Kostyshin, L. V. Boichuk, S. V. Goroshin, Combust. Explos. Shock Waves 29 (1993) 163-169.

[5] L. V. Boichuk, V. G. Shevchuk, A. I. Shvets, Combustion, Explosions, and Shock Waves 38 (2002) 651-654.

[6] S. Goroshin, I. Fomenko, J. Lee, Proc. Combust. Inst. 26 (1996) 1961-1967.

[7] G. Risha, Y. Huang, R. Yetter, V. Yang, in: 43rd AIAA Aerospace Sciences Meeting and Exhibit, American Institute of Aeronautics and Astronautics, 2005.

[8] P. Julien, J. Vickery, S. Goroshin, D. L. Frost, J. M. Bergthorson, Combust. Flame 162 (2015) 4241-4253.

[9] A. Wright, S. Goroshin, A. Higgins, Combust. Sci. Technol. 188 (2016) 2178-2199.

[10] X. Mi, A. J. Higgins, S. Goroshin, J. M. Bergthorson, Proc. Combust. Inst. 36 (2016) 2359-2366. 
[11] P. Julien, S. Whiteley, M. Soo, S. Goroshin, D. L. Frost, J. M. Bergthorson, Proc. Combust. Inst. 36 (2017) 2291-2298.

[12] S. Goroshin, M. Bidabadi, J. Lee, Combust. Flame 105 (1996) 147-160.

[13] R. Lomba, S. Bernard, P. Gillard, C. Mounaim-Rousselle, F. Halter, C. Chauveau, T. Tahtouh, O. Guézet, Combust. Sci. Technol. 188 (2016) 1857-1877.

[14] A. D. Rakic, A. B. Djurišic, J. M. Elazar, M. L. Majewski, Appl. Opt. 37 (1998) 5271-5283.

[15] J. Arnold, E. Whiting, G. Lyle, J. Quant. Spectrosc. Radiat. Transf. 9 (1969) 775-798.

[16] H. Partridge, S. R. Langhoff, B. Lengsfield, B. Liu, J. Quant. Spectrosc. Radiat. Transf. 30 (1983) 449-462.

[17] J. Coxon, S. Naxakis, Journal of Molecular Spectroscopy 111 (1985) 102113.

[18] I. Glassman, R. Yetter, Combustion, Elsevier Inc., 4th edition, 2008.

[19] J. Glorian, S. Gallier, L. Catoire, Combust. Flame 168 (2016) 378-392.

[20] L. Montgomery Smith, D. R. Keefer, S. Sudharsanan, J. Quant. Spectrosc. Radiat. Transf. 39 (1988) 367-373.

[21] M. Soo, S. Goroshin, N. Glumac, K. Kumashiro, J. Vickery, D. L. Frost, J. M. Bergthorson, Combust. Flame 180 (2017) 230-238. 


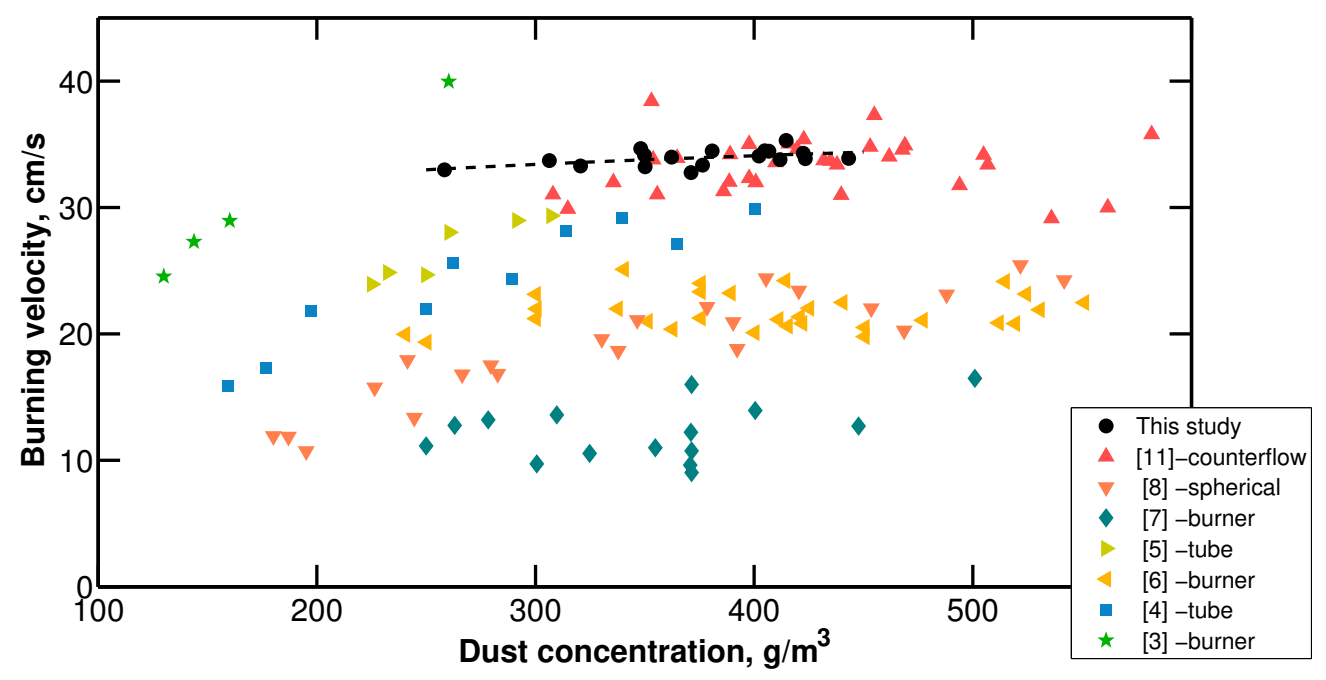

Figure 9: Burning velocities for aluminum-air flames at different dust concentrations. 